\title{
Visual evoked responses to visual-spatial and verbal stimuli: Evidence of differences in cerebral processing
}

\author{
M. D. RUGG and J. G. BEAUMONT \\ University of Leicester, Leicester, England
}

\begin{abstract}
The experiment utilized visual evoked responses (VERs) to investigate lateral asymmetries in the processing of visually presented stimuli. VERs were elicited by letter stimuli requiring verbal analysis and nonverbal pattern stimuli requiring visuospatial analysis. The first positive component $\left(P_{75}\right)$ was found to be of a shorter latency in the right hemisphere for both stimulus types. The amplitude of the component $P_{230}-\mathrm{N}_{265}$ was found to be greater in both hemispheres when VERs were elicited by the letter stimuli. It is concluded that the right hemisphere was preeminent in the early stages of the processing of both stimulus types and that $P_{230}-N_{265}$ reflected a bilateral component of verbal processing.
\end{abstract}

Evidence regarding the relative specializations of the cerebral hemispheres in the processing of different types of information is well documented (Milner, 1975). The weight of this evidence suggests strongly that in the majority of individuals verbal tasks are mediated predominantly by the left hemisphere, visuospatial tasks by the right hemisphere. Efforts to index these asymmetries in information processing in the hemispheres using evoked responses have met with varied amounts of success [see Butler \& Glass (1976) and Donchin, Kutas, $\&$ McCarthy (1977) for thorough reviews]. In the case of visual evoked responses (VERs), some investigators have reported lateral asymmetries which appear to be related to the type of processing in which their subjects were engaged. For example, Buchsbaum and Fedio (1969) elicited VERs with words or random dot patterns and found a major component of the VER to be of shorter latency when elicited by words, this effect being greater over the left hemisphere. Preston, Guthrie, Kirsch, Gertman, and Childs (1977) elicited VERs by word or flash stimuli. The waveforms produced by these stimuli were found to be more disparate over the left hemisphere than the right. In contrast to these two studies, Shelburne $(1972,1973)$ reported no differences between the hemispheres in VERs elicited by series of letters forming words or nonsense syllables.

To date, no study has elicited VERs with stimuli the processing of which might be expected to preferentially engage the right hemisphere, for example, the utilization of nonverbal stimuli requiring visuospatial processing. The present study compared VERs elicited by two types of simple stimuli. Appropriate responses necessitated

The first author is supported by the Social Science Research Council of the U.K. Reprint requests should be sent to M. D. Ruggs, Department of Psychology, University of York, York, England. verbal processing for which the left hemisphere was considered to be specialized or visuospatial processing, considered to involve processing predominantly in the right hemisphere.

\section{METHOD}

Subjects

Ten right-handed subjects, five of each sex were employed.

Stimuli

These were presented via a Digital VR14 display oscilloscope. Two sets of stimuli were employed, one set consisting of letters of the alphabet and the other of letter-like nonsense patterns (see Figure 1 for examples). The stimuli were approximately $6.5 \mathrm{~mm}$ across and were viewed from a distance of $500 \mathrm{~mm}$. They subtended a visual angle of $32^{\prime}$ across the visual midline on exposure. The intensity of each stimulus was approximately $13 \mathrm{~cd} / \mathrm{m}^{2}$ and exposure duration was $60 \mathrm{msec}$.

There were two blocks of each stimulus type. Each block consisted of 50 stimuli, randomly chosen from the appropriate pool of stimuli with the constraint that 10 of those included be targets. In the case of the letters, a target was any letter containing the sound "ee." For the nonverbal patterns, targets were those stimuli which were symmetrical about the vertical axis. To minimize subjects' anticipatory responses, the interstimulus intervals varied randomly, being either 2 or 3 sec.

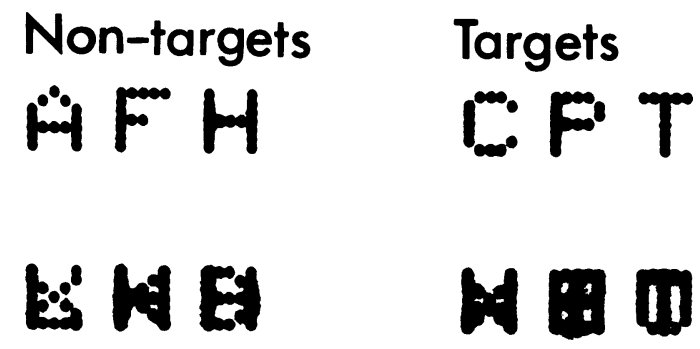

Figure 1. Examples of target and nontarget verbal and visuospatial stimuli. 


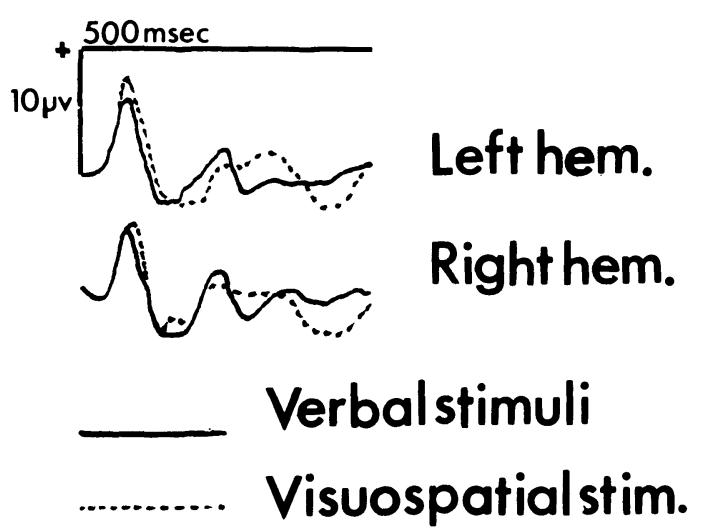

Figure 2. One subject's VERs from each hemisphere in each condition.

\section{Procedure}

Subjects were seated in a darkened room facing the display oscilloscope with their heads resting on a chinrest. They were instructed to fixate constantly on a small central fixation dot which was present on the screen in the absence of a stimulus. They were informed that in each stimulus block the target stimuli were relatively uncommon. This instruction was intended to minimize the effect that a gradual learning over the session of these relative frequencies might have had. The required response was a slight raising of the right index finger, which was situated under the lever of a microswitch. The switch was connected to the Lab/8e computer controlling the display of the stimuli and allowed the computation of the mean reaction-time to target stimuli in each block, the number of correct responses to targets (hits), and the number of false positives. The four stimulus blocks were presented in an ABBA design counterbalanced across subjects. The subjects were given a short break between the blocks and were informed prior to each block as to the nature of the stimuli that would appear.

\section{EEG Recording}

To record each subject's EEG, silver/silver chloride cup electrodes containing "Neptic" jelly were affixed with collodion cement at homologous left and right sites $25 \%$ of the distance from the occipital $\left(\mathrm{O}_{1}, \mathrm{O}_{2}\right)$ to the posterior temporal $\left(\mathrm{T}_{5}, \mathrm{~T}_{6}\right)$ placements of the $10-20$ system (Jasper, 1958). $C_{z}$ served as the reference for both channels, and the right mastoid was grounded. The positions of the exploring electrodes were chosen to maximize the detection of activity in the visual cortex and the adjacent association cortex in the angular gyrus region [the left angular gyrus is implicated in the mediation of the processes involved in visual-to-verbal translation (Geschwind, 1962)]. The EEG signals were fed into two matched channels of a Devices high-gain ac amplifier with low-pass settings $3 \mathrm{~dB}$ down at $25 \mathrm{~Hz}$ and time-constant $.3 \mathrm{sec}$. The gain of each channel was $20 \mathrm{k}$ and their outputs were recorded on two channels of a Racal F.M. tape recorder prior to off-line analysis. The amplifiers used to record left and right channels of EEG were alternated over subjects to counterbalance any residual inequalities.

VERs to the two types of stimuli were formed using Digital system software on a Lab/8e computer. The two samples of EEG associated with each stimulus type were pooled and VERs were formed from the $500 \mathrm{msec}$ of EEG following each nontarget stimulus; the number of eliciting stimuli was thus 80 for each VER. The EEG data therefore consisted of subjects' VERs recorded over each hemisphere. They were elicited by two types of stimuli which required different modes of processing to facilitate an appropriate response.

\section{RESULTS}

One subject's VERs did not show any clearly recognizable components, and the data obtained from this subject were not used in any subsequent analysis. Four components were consistently recognizable in the VERs of the remaining nine subjects. These were a positive peak around $75 \mathrm{msec}, \mathrm{P}_{75}$, a negative trough around $155 \mathrm{msec}, \mathrm{N}_{155}$, another positive peak around $230 \mathrm{msec}, \mathrm{P}_{230}$, and a late negative component around $265 \mathrm{msec}, \mathrm{N}_{265}$. Typical VERs are illustrated in Figure 2.

\section{Latencies}

The mean latencies of each peak and trough are shown with the associated standard deviations in Table 1. Separate two-way ANOVAs with repeated measures were performed on the latencies of each component. The ANOVA performed on the $\mathbf{P}_{75}$ data revealed a significant ${ }^{1}$ hemisphere effect $[F(1,8)=$ 5.32]. This was due to the latency of $P_{75}$ from the right hemisphere being shorter than that from the left in both conditions. No other ANOVA gave rise to any significant effects.

\section{Amplitudes}

The means and standard deviations of the components, $\mathrm{P}_{75}-\mathrm{N}_{155}, \mathrm{~N}_{155} \cdot \mathrm{P}_{230}$, and $\mathrm{P}_{230}-\mathrm{N}_{265}$, are shown in Table 2. Only the analysis of the $\mathrm{P}_{230}-\mathrm{N}_{265}$ data revealed a significant effect. This was for tasks $[F(1,8)=21.46]$ and was due to this component's being considerably larger in the VERs elicited by the letter stimuli compared to that in the VERs from the nonverbal patterns.

Table 1

Mean Latency (in Milliseconds) of VER Components by Task and Hemisphere

\begin{tabular}{|c|c|c|c|c|c|c|c|c|}
\hline \multirow[b]{3}{*}{ Component } & \multicolumn{4}{|c|}{ Visuospatial Task } & \multicolumn{4}{|c|}{ Verbal Task } \\
\hline & \multicolumn{2}{|c|}{ Left Hemisphere } & \multicolumn{2}{|c|}{ Right Hemisphere } & \multicolumn{2}{|c|}{ Left Hemisphere } & \multicolumn{2}{|c|}{ Right Hemisphere } \\
\hline & Mean & SD & Mean & SD & Mean & SD & Mean & SD \\
\hline $\begin{array}{l}P_{75} \\
N_{155} \\
P_{230} \\
N_{265}\end{array}$ & $\begin{array}{r}77.3 \\
154.0 \\
237.5 \\
264.4\end{array}$ & $\begin{array}{r}5.9 \\
15.4 \\
26.8 \\
16.4\end{array}$ & $\begin{array}{r}75.2 \\
151.8 \\
234.9 \\
261.1 \\
\end{array}$ & $\begin{array}{r}7.5 \\
19.2 \\
25.2 \\
16.4\end{array}$ & $\begin{array}{r}80.4 \\
155.1 \\
231.1 \\
266.8 \\
\end{array}$ & $\begin{array}{l}11.0 \\
11.4 \\
24.4 \\
19.8 \\
\end{array}$ & $\begin{array}{r}72.9 \\
154.3 \\
228.7 \\
263.1 \\
\end{array}$ & $\begin{array}{r}8.9 \\
20.2 \\
23.7 \\
23.8 \\
\end{array}$ \\
\hline
\end{tabular}


Table 2

Mean Amplitude (in Microvolts) of VER Components by Task and Hemisphere

\begin{tabular}{|c|c|c|c|c|c|c|c|c|}
\hline \multirow[b]{3}{*}{ Component } & \multicolumn{4}{|c|}{ Visuospatial Task } & \multicolumn{4}{|c|}{ Verbal Task } \\
\hline & \multicolumn{2}{|c|}{ Left Hemisphere } & \multicolumn{2}{|c|}{ Right Hemisphere } & \multicolumn{2}{|c|}{ Left Hemisphere } & \multicolumn{2}{|c|}{ Right Hemisphere } \\
\hline & Mean & SD & Mean & SD & Mean & SD & Mean & SD \\
\hline $\begin{array}{l}P_{75}-N_{155} \\
N_{155}-P_{230} \\
P_{230}-N_{265}\end{array}$ & $\begin{array}{r}14.23 \\
7.67 \\
1.52 \\
\end{array}$ & $\begin{array}{l}4.58 \\
4.59 \\
1.58 \\
\end{array}$ & $\begin{array}{r}14.28 \\
8.41 \\
1.35 \\
\end{array}$ & $\begin{array}{l}5.70 \\
5.41 \\
1.12 \\
\end{array}$ & $\begin{array}{r}13.10 \\
8.35 \\
4.01 \\
\end{array}$ & $\begin{array}{l}4.02 \\
4.20 \\
2.58 \\
\end{array}$ & $\begin{array}{r}13.49 \\
7.78 \\
3.35 \\
\end{array}$ & $\begin{array}{l}5.98 \\
4.38 \\
1.78 \\
\end{array}$ \\
\hline
\end{tabular}

\section{Behavioral Data}

Means of the three recorded performance measures are shown for each task (pooled blocks) in Table 3. No significant differences between pairs of means were found. The large, but nonsignificant, difference between tasks in the means of the false positive responses is due to the inordinately large number of such responses (30) made by one subject in the visuospatial condition.

\section{DISCUSSION}

The behavioral data suggest that the tasks associated with the different stimulus types did not differ in difficulty. Thus the difference in VERs associated with the different stimuli are unlikely to be due to the factor of task difficulty.

The latency data revealed that $\mathbf{P}_{75}$ from the right hemisphere showed a significantly shorter latency compared to the left in both conditions. This may be interpreted as revealing a preeminence on the part of the right hemisphere for the initial stages of processing whether the task associated with the information be verbal or nonverbal. This explanation is supported by the findings of a reaction-time study by Bryden and Allard (1976), who demonstrated that the normally reliable right visual field advantage for letter recognition could be reversed by the use of complex and unfamiliar typefaces. They interpreted this as demonstrating the preeminence of the right hemisphere in all visual processing. This preeminence overshadowed the left-hemisphere advantage for verbal processing when the visual processing required was of more than a certain level of complexity. The notion of right-hemisphere preeminence for visual processing receives further support from Kimura and Durnford (1974) and Meyer (1976), the latter arguing, on the basis of a hemisphere asymmetry in the strength of the McCollough effect, that asymmetry of processing exists at the level of the primary visual cortex. If it is assumed that $P_{75}$ originates in the striate cortex (Jeffreys, 1971; Regan, 1972), then the present study supports Meyer's hypothesis.

The amplitude data revealed no task-dependent lateral differences in subjects' VERs. Of interest, however, is the finding that the latest component analyzed, $\mathrm{P}_{230}-\mathrm{N}_{265}$, was of a considerably greater magnitude in the VERs elicited by the letter stimuli compared to those elicited by the nonverbal patterns.
As this component occurred so late in the VER, it is highly unlikely that the observed differences were due to differences in the physical nature of the two sets of eliciting stimuli; effects of this nature are observed in the early components of the evoked response (Regan, 1972). Late components are considered to reflect the psychological state and cognitive processes of the subject (Donchin et al., 1977). Thus, it is likely that the effect is due in some way to differences in subjects' modes of information processing, i.e., visuospatial compared to verbal. That the component showed no lateral asymmetry suggests that it reflects some nonlateralized aspect of verbal processing, perhaps because under the conditions of the present study the verbal task employed has a more bilateral component than previously suspected. In view of recent work suggesting that receptive language capacities may have quite extensive bilateral representation (Day, 1977; Zaidel, 1976, 1977; for a review, see Searleman, 1977), this explanation may have some validity.

An alternative explanation, however, is that the difference observed in the VERs to the verbal and nonverbal stimuli was due to differential activity at the reference electrode rather than the exploring ones. Had this activity been asymmetric, it is likely that this would have been observed, as an asymmetrically placed locus of activity might have been expected differentially to effect the exploring electrodes. Thus, it is arguable that wherever the locus of the activity giving rise to the observed effect, it most probably reflects bilaterally distributed cortical activity. Further research, utilizing an electrode montage more appropriate for the study of centrally distributed ER components, should elucidate this point.

While this study demonstrated no task-dependent asymmetries in the VER, it is arguable that these were missed, as the VERs elicited by the most task-relevant

Table 3

Mean Reaction Time (in Milliseconds), Hits, and False Positives for Each Task

\begin{tabular}{lrrrrr}
\hline & \multicolumn{2}{c}{ Visuospatial Task } & & \multicolumn{2}{c}{ Verbal Task } \\
\cline { 2 - 3 } \cline { 6 - 6 } & Mean & SD & & Mean & SD \\
\hline Reaction Time & 615.0 & 59.3 & & 621.0 & 66.5 \\
Hits & 16.6 & 3.2 & & 17.3 & 1.2 \\
False Positives & 8.0 & 9.0 & & 1.0 & 3.2 \\
\hline
\end{tabular}


stimuli, the targets, were not recorded. However, any such asymmetries would, if found, have been related to processes initiated following target recognition and not to the initial analysis of the stimuli leading up to target recognition, the processes involved in which being the focus of the present study. The possibility of taskdependent lateral asymmetries associated with postrecognition processes is at present being investigated in this laboratory.

\section{REFERENCES}

Bryden, M. P., \& Allard, F. Visual hemifield differences depend on typeface. Brain and Language, 1976, 3, 191-200.

Buchsbaum, M., \& Fedio, P. Visual information and evoked responses from the left and right hemispheres. Electroencephalography and Clinical Neurophysiology, 1969, 26, 266-272.

Butler, S. R., \& Glass, A. EEG correlates of cerebral dominance. In A. R. Riesen \& R. F. Thompson (Eds.), Advances in psychobiology (Vol. 111). New York: Academic Press, 1976.

DAY, J. Right-hemisphere language processing in normal righthanders. Journal of Experimental Psychology: Human Perception and Performance, 1977, 3, 518-528.

Donchin, E., Kutas, M., \& McCarthy, G. Electrocortical indices of hemispheric utilization. In S. Harnad, R. W. Doty, L. Goldstein, J. Jaynes, \& G. Krauthamer (Eds.), Lateralization in the nervous system. New York: Academic Press, 1977.

GESCHWIND, N. The anatomy of acquired disorders of reading. In J. Money (Ed.), Reading disability. Baltimore: John Hopkins Press, 1962.

JASPER, H. H. The ten twenty system of the international federation. Electroencephalography and Clinical Neurophysiology, 1958, 10, 371-375.

JEFFREYs, D. A. Cortical source locations of pattern-related visual evoked potentials recorded from the human scalp. Nature, 1971, 229, 502-504.
Kimura, D., \& DURnford, M. Normal studies on the function of the right hemisphere in vision. In S. J. Dimond \& J. G. Beaumont (Eds.), Hemisphere function in the human brain. London: Paul Elek, 1974.

MEYER, G. E. Right hemisphere sensitivity for the McCollough effect. Nature, 1976, 264, 751-753.

Milner, B. Hemispheric specialization and interaction. Cambridge, Mass: MIT Press, 1975.

Preston, M. S., Guthrie, J. T., Kirsch, I., Gertman, D., \& ChILds, B. VER's in normal and disabled readers. Psychophysiology, 1977, 14, 8-14.

REGAN, D. Evoked potentials in psychology, sensory physiology and clinical medicine. London: Chapman and Hall, 1972.

Searleman, A. A review of right hemisphere linguistic capabilities. Psychological Bulletin, 1977, 84, 503-528.

ShelbuRne, S. A. Visual evoked responses to word and nonsense syllable stimuli. Electroencephalography and Clinical Neurophysiology, 1972, 32, 17-25.

Shelburne, S. A. Visual evoked responses to language stimuli in normal children. Electroencephalography and Clinical Neurophysiology, 1973, 34, 135-143.

ZAIDEL, E. Auditory vocabulary of the right hemisphere following brain bisection or hemidecortication. Cortex, 1976, 12, 191-211.

ZAIDEL, E. Unilateral auditory language comprehension on the token test following cerebral commisswotomy and hemispherectomy. Neuropsychologia, 1977, 15, 1-18.

\section{NOTE}

1. The .05 rejection region was adopted in all statistical tests.

Received for publication February 9, 1978; revision accepted May 26, 1978.) 